\title{
Conf $-931018-85$
}

UCRL-JC-114265

PREPRINT

\section{Study on Current Sharing Phenomena Observed During the Testing of ITER Prototype Cable-in-Conduit Conductors in the FENIX Test Facility}

Young J. Lee, Robert L. Wong, and Stewart S. Shen

This paper was prepared for submittal to the

Proceedings of the 15th Symposium on Fusion Engineering

Hyannis, MA

October 11-15, 1993

October 6, 1993

This is a preprint of a paper intended for publication in a journal or proceed ings. Since hanges may be made before publication, this preprint is made available with the Inderstanding that it will not be cited or reproduced without the permission of the Iuthor. 


\section{DISCIAIMER}

This document was prepared as an account of work sponsored by an agency of the United States Governmeri. Neither the United States Government nor the University of California nor any of their employees, makes any warranty; express or implied, or assumes any legal liability or responsibility for the accuracy; completeness, or usefulness of any information, apparatus, produch, or process disclosed, or represents that its use would not infringe privacely oxned rights. Reference herein to any specific commercial products, process, or service by trade name. trademark, manufacturer, or otherkise, does not necessarily constitute or imply its endorsement, recommendation. or favoring by the United States Governm ant or the University of California. The views and opinions of authors expressed herein do not necessarily state or reflect those of the United States Government or the University of California, and shall not be used for advertising or product endorsement purposes. 


\title{
Study on Current Sharing Phenomena Observed During the Testing of ITER Prototype Cable-in-Conduit Conductors in the FENIX Test Facility
}

\author{
Young J. Lee \\ ICF Kaiser Engineers \\ 1800 Harrison Street, Oakland, Califomia 94623 \\ Robert L. Wong, and Stewart S. Shen \\ Lawrence Livermore National Laboratory \\ P.O. Box 808, Livermore, California 94550
}

\begin{abstract}
Current sharing phenomena were studied during the testing of ITER (International Thermonuclear Experimental Reactor) prototype sample conductors in the FENIX (Fusion Engineering International Experiments) test facility at the Lawrence Livermore National Laboratory. During steady-state operation in the current sharing region, voltage drops of up to $200 \mu \mathrm{V}$ were measured across the conductor. These experimental results were studied in detail using computer program CICC. Differences between the computer predictions and experimental results are postulated to be due to interstrand cross-currents.
\end{abstract}

\section{INTRODUCTION}

The cable-in-conduit conductor (C.ICC.) is considered the prime candidate for use in the cryogenic superconducting toroidal and poloidal field coil by the ITER [1]. It is made by (wisting copper stabilized $\mathrm{Nb}_{3} \mathrm{Sn}$ superconducting wires into cables and enclosing them tightly in a conduit. The conductor is cooled by forcing supercritical helium through the spaces between the twisted superconducting wires. Performance testing of the full size conductor at the design conditions of $40 \mathrm{kA}$ and $12.5 \mathrm{~T}$ was conducted at the FENIX test facility at Lawrence Livermore National Laboratory [2]. One of the test objectives was to study the performance of the conductor at current sharing conditions. The test results show that the conductor can maintain steady-state operation at current sharing conditions with the voltage drop of up to 200 $\mu \mathrm{V}$ across the conductor. The voltage drop phenomenon was studied using the computer program $C I C C$ developed by Wong [3].

\section{A BRIEF DESCRIPTION OF THE FENIX TEST}

Various types of the cable-in-conduit conductors have been tested at the FENIX test facility at the Lawrence Livermore National Laboratory since December of 1991. The test results have been discussed in detail elsewhere [4]. Samples prepared for the test consist of straight, paired conductors, connected in series together at one end and connected to the FENIX busbars at the other end. The length of each conductor, including termination, is $4.7 \mathrm{~m}$. The conductor was cooled by supercritical helium at $5-7$ atm pressure. The background magnetic field of $12.5 \mathrm{~T}$ at the center of the conductor was produced by the FENIX magnets. The typical background magnetic field along the conductor length is shown in Fig. 1. In addition to the background ficld, a self magnetic field will be generated by the current passing through the conductor.

Five CICC samples have been tested at the facility. Only two of these have been examined for this analysis: a conductor manufactured by the European Community (NET/EM-LMI) and a conductor provided by Japan (JAERI) $[5,6]$. The major physical parameters of these conductors are summarized in Table 1 . To observe the current sharing phenomena, the inlet temperature of the helium was slowly increased until the voltage across the conductor was detected. When the voltage across the conductor was detected, the system was maintained at steady-state. Voltage drops and the temperature of the conductor wall at the center of the conductor were recorded. The voltage drops were recorded by pairs of voltage tans attached at the conductor wall actoss the high field region of the conductor. All the voltage measurements showed the same value, indicating that the voltage drop occurs at the high fie'd region of the conductor.

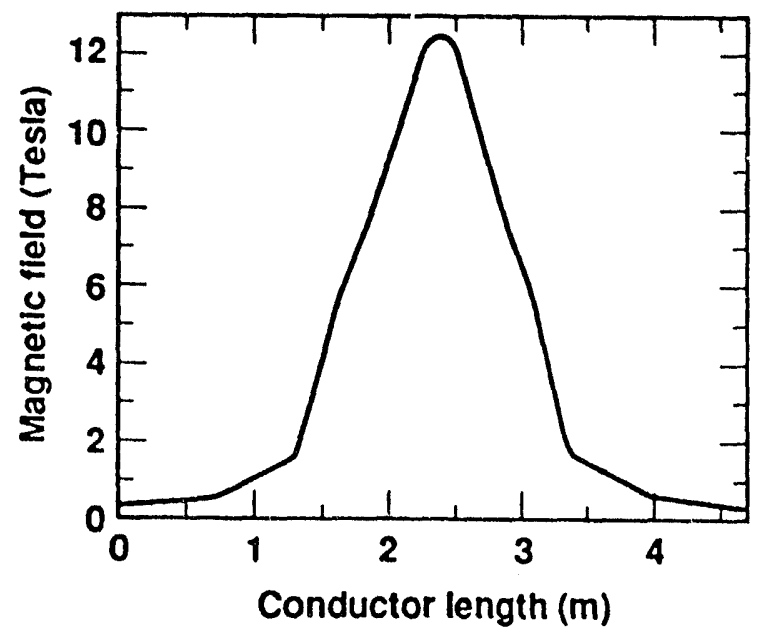

Fig. 1 Background Magnelic Field Suengul Along the Conductor Length at the FENIX Test Facility

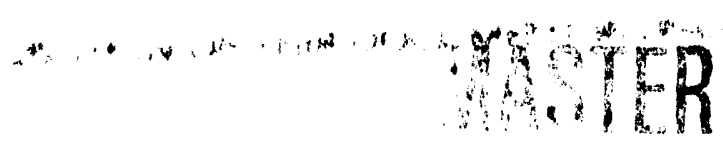


TABLE I

Main Physical Parameters of Conductors

\begin{tabular}{lcl}
\hline & EM-LMI & JAERI \\
\hline & 864 & 23 \\
Number or Strands & 0.78 & 2.4 \\
Strand Diameler(mm) & 361 & 126 \\
He Area $\left(\mathrm{mm}^{2}\right)$ & 806 & 301 \\
Cable Space Cross Section $\left(\mathrm{mm}^{2}\right)$ & 0.55 & 0.654 \\
Fraction of Cu Area(mm &
\end{tabular}

The voltage drop in the conductor as a function of helium temperature is plotted in Fig. 2 and 3 for the EM-LMI conductor and JAERI conductor respectively. The temperature measurement at the conductor wall is assumed to be the average of the helium inlet and outlet temperatures of the conductor. The helium inlet and outlet temperatures are calculated from energy balance assuming there is no energy loss through the conductor wall. As shown in these figures, the voltage drop slowly increased to $200 \mu \mathrm{V}$ as the helium oudet temperature increased from $5.2 \mathrm{~K}$ to $7.2 \mathrm{~K}$ for EM-LMI conductor, and increased to $30 \mu \mathrm{V}$ as the temperature increased from $5.8 \mathrm{~K}$ to $6.6 \mathrm{~K}$ for JAERI conductor. When the helium outlet temperature is increased further, the conductor quenches.

\section{ANAL YSIS OF THE CURRENT SHARING PHENOMENA USING COMPUTER PROGRAM CICC}

The current sharing phenomena observed at the FENIX test facility were studied using the computer program CICC. This program, developed by Robert Wong at the Lawrence Livermore National Lahoratory, models transient thermodynamic and fluid-dynamic state of the helium coolant in the CICC. The computational algorithm in the code couples a one-dimensional compressible pipe model with a two-dimensional axisymmetric heat conduction model of the superconductor cables, the conduit and the

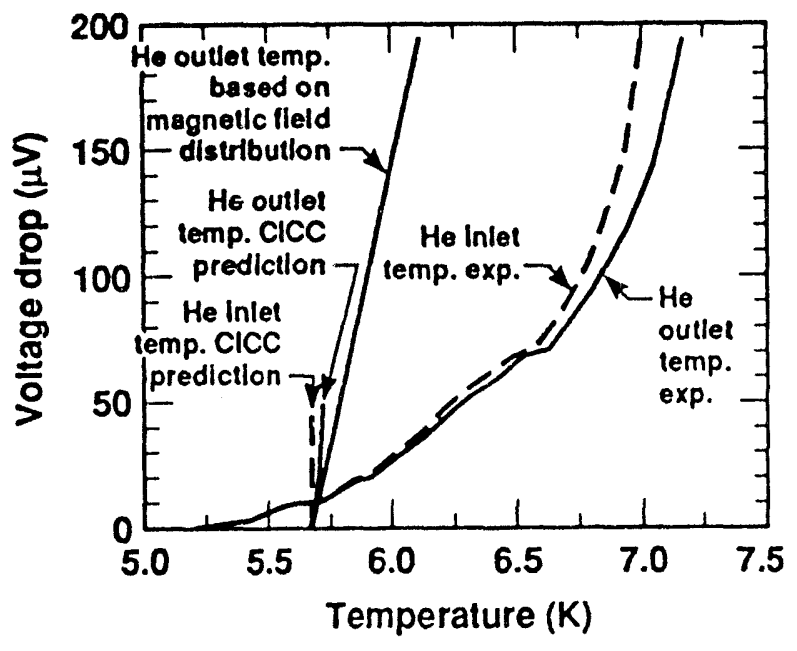

Fig. 2 Voltage drop as a function of He temperature for EM-LMI conducto-expreriment data and CICC predictions.

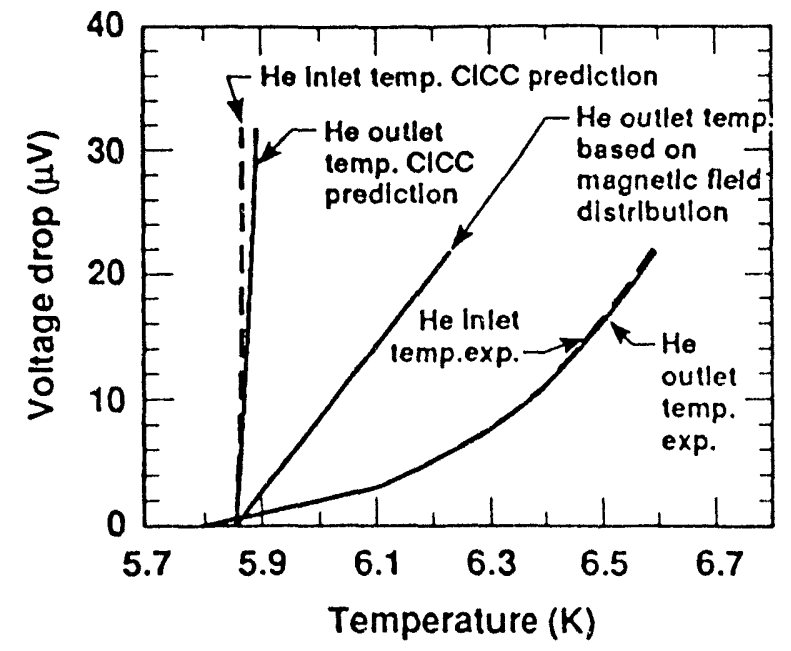

Fig. 3 Voltage drop as a function of He temperalure for JAERI conductor .. experimental data and $C C / C$ predictions.

insulation. The code also calculates the heat generation rate and voltage rise in the superconductor cables during the current sharing conditions. Since the code treats the hclium now as one-dimensional pipe flow, the parameters of the cable space are assumed to be uniform across any crosssection. The code with its present structure can not account for non-uniform current superconducting properties, such as magnetic field, strain and temperature in calculating the critical current of the superconducting strands.

To begin the calculation, the steady-state operating condition just below the current sharing temperature was established at the measured helium flow rate. After establishing this steady-state condition, the helium inlet temperature was gradually increased until the voltage drop across the conductor appeared. However, the code predicts that the conductor cannot be operated stably at steady-state under any current sharing condition, even $10^{-5} \mathrm{~K}$ above the starting temperature of the current sharing. The code can predict the steady-state operation of the conductor under current sharing conditions when the conductor heat transfer area is increased significantly. The increase required to maintain steady-state under current sharing conditions depends on the type of conductor and the amount of the voltage drop. This behavior is an agreement with tests of single superconductor strands.

The results obtained by the code with the heat transfer area increased by 100 are summarized in the Fig. 4 and 5 for the EM-LMI conductor with a $5.67 \mathrm{~K}$ helium inlet temperature. Fig. 4 shows the voltage drop across the conductor, and Fig. 5 displays the helium temperature variation along the conductor $20 \mathrm{~s}$ after current sharing condition begins. Fig. 4 shows that the conductor reaches steady-state within $5 \mathrm{~s}$ by the computer simulation.

The voltage drop across the conductor calculated by the CICC code is plotted as a function of the helium inlet and outlet temperature along with the experimental data in Fig. 2 and 3 for EM-LMl conductor and JAERI conductor respectively. As demonstrated in these Figures, the voltage 


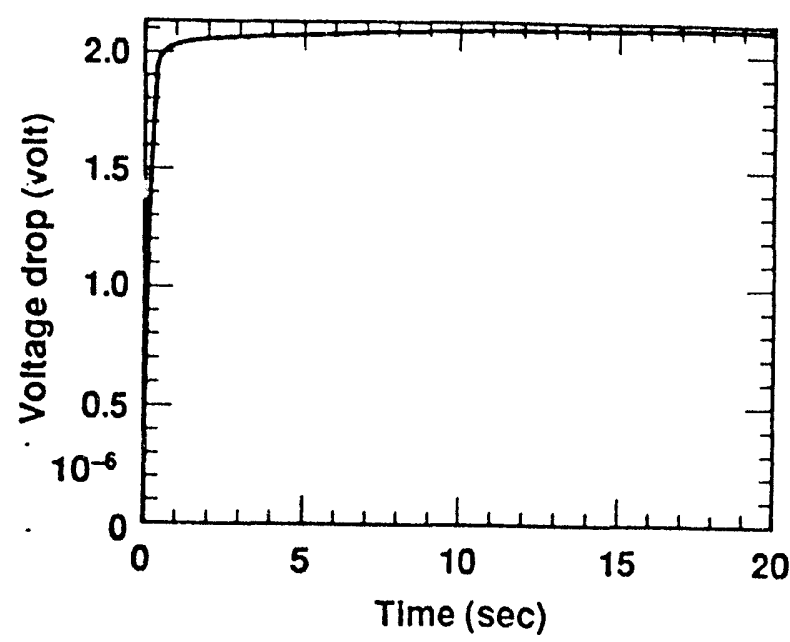

Fig. 4 Voleage drop across the conducior as a function of ume (EM-LMI conducior).

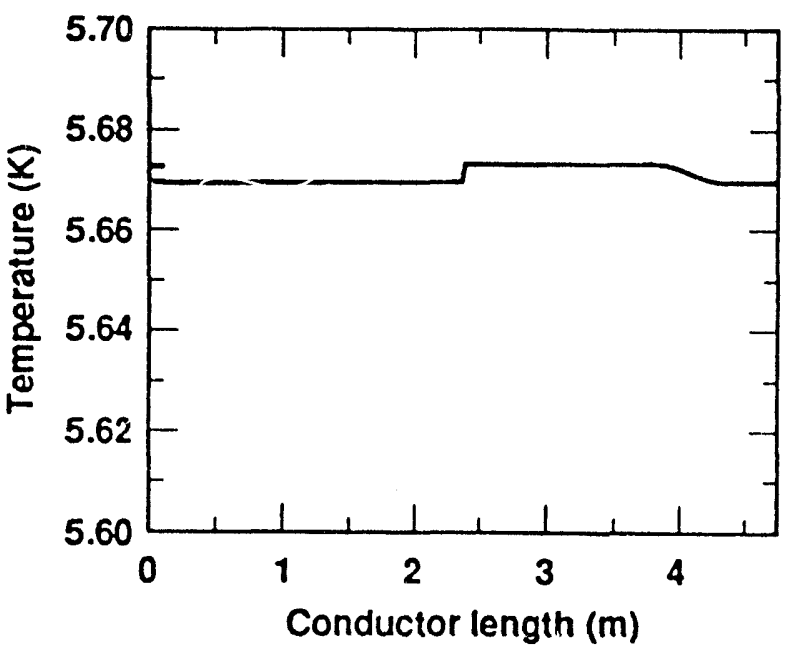

Fig. 5 He temperature variation along the conductor length after $20 \mathrm{~s}$ (EM. LMI conductor).

drop due to current sharing predicted by the code increases much more sharply with temperature increase than does the experimental data. The code predictions represent the commonly understood one-dimensional current sharing phenomena in which the excess current from the superconducling wires passes through adjacent copper. The voltage drop observed in the FENIX test cannot be explained by this one-dimensional current sharing model. Additional modeling including cable-space non-uniformities is needed.

The differences between experimental data and code predictions (Fig. 2 and 3 ) in the quench temperature are caused by the selecting lower strain values in the code, and it will not effect the analysis.

\section{DISCUSSION ON THE DISCREPANCY BETWEEN EXPERIMENTAL DATA AND CODE PREDICTION}

Part of the discrepancy between the experimentally observed voltage drop and that predicted by the code can be explained by inter-strand cross-currents due to the non-uniform magnetic field across the radial direction in the conductor. As discussed in the previous section, the CICC code assumes uniform magnetic field across the cable space. The total magnetic field in the conductor is the sum of three contributions: the background field produced by the FENIX magnets, the self field of the individual leg and the field generated by the neighboring leg. When the sample carries a large current, a gradient of magnetic field occurs across the cable space. The magnetic field distributions in both EM. LMI and JAERI conductors are shown in Fig. 6 (a) and (b) respectively. The average, maximum and minimum fields are summarized in Table II for both conductors.

The critical current of the strands is not only function of temperature but also the magnetic field. The critical current will not be the same for all strands; the critical current is smaller for strands in a higher magnetic field. If the current is initially distributed in the conductor based on the critical current variation, the voltage drop due to the current sharing will be the same as the uniform field as calculated in the CICC code. However, the current is not distributed based on the critical current variation. Rather it will be distributed uniformly if the inlet and oudet connections are designed properly. If the current is uniformly distributed throughout all the strands, and the strands have different critical current values due to the magnetic ficld distribution, the current in the strand with the lowest critical current value will transfer its current to the strand with a larger critical current value when the temperature of the conductor becomes higher than the current sharing temperature of the strand with the lowest critical current.

This phenomenon is quite different from the commonly known current sharing phenomena where the excess current is transferted through the copper altached to the superconducting material. Furthermore, the low voltage drop during the inter-strand cross-currents phenomena indicates that most of the cross-currents occur at the busbar where the resistance between the strands is minimum. The resulting cross-currents can explain 23\% of current sharing temperature range during the current sharing observed in the FENIX Iest in EM-LMI conductor and $47 \%$ in JAERI

TABLE II

Magnetic Field Strength at High Field Region

\begin{tabular}{lccc}
\hline & \multicolumn{3}{c}{ Magnetic Field (T) } \\
& Average & Maximum & Minimum \\
\hline EM-LMI Conductor & 12.5 & 12.96 & 12.04 \\
JAERI Conductor & 12.0 & 12.41 & 11.59
\end{tabular}




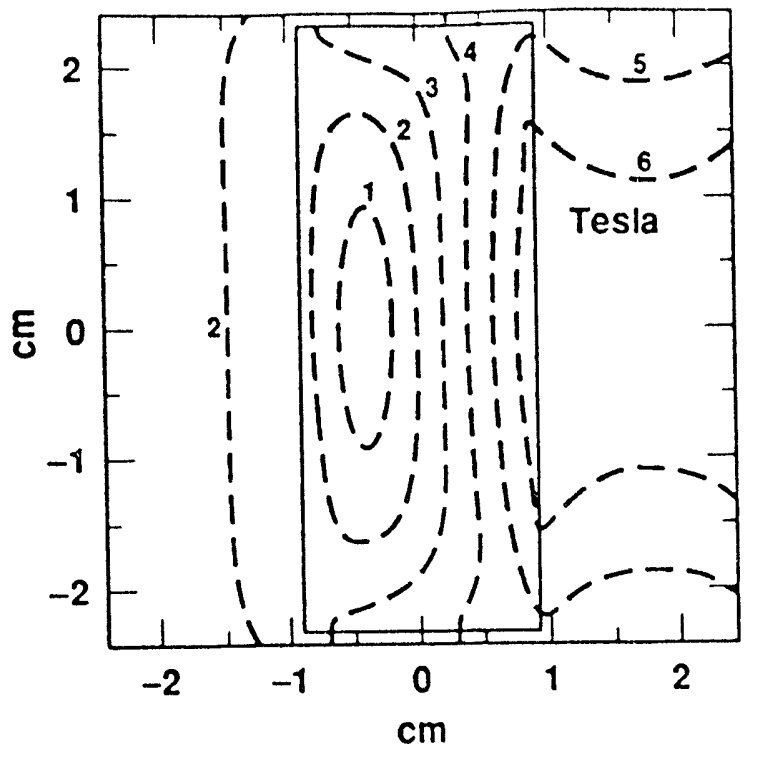

(a) EM-LMI Conductor

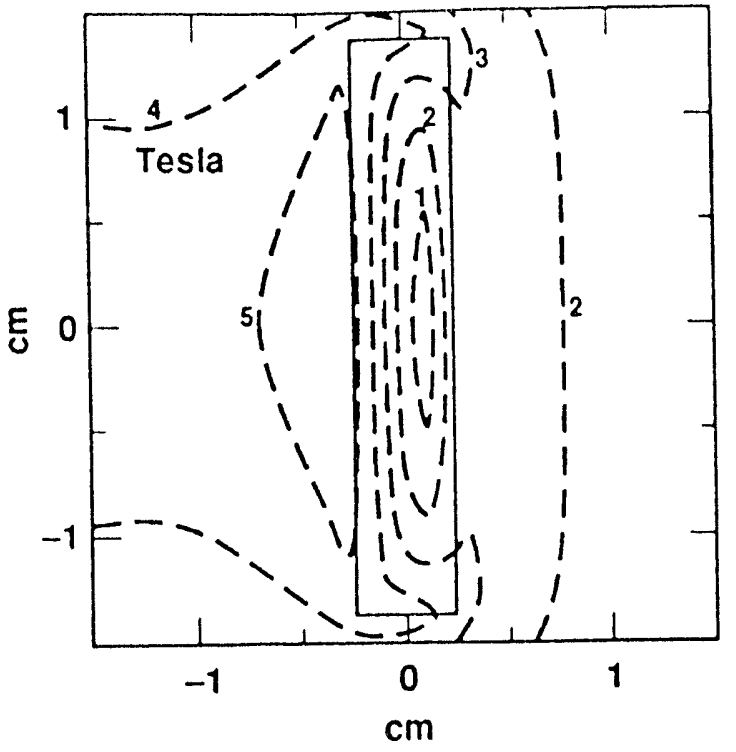

(b) JAERI Conductor

Fig. 6 Distribution of dee self field over the sample across section

conductor. Voltage drop caused by the local magnetic field variation vs. helium outlet temperature was plotted in Fig. 2 and 3 for EM-LMI and JAERI conductor respectively. It was assumed that the voltage drop varied linearly with the amount of the cross-current caused by the local inagnetic field variation.

The rest of the voltage drop resulting in a large current sharing temperature range can be explained by other phenomena. The design of the busbar connections may produce a non-uniform conductor current distribution. The strand with the highest current will transfer its current to other strands as the conductor temperature increases. This effect on the voltage drop could be much larger than that due to the magnetic field if the magnitude of the non-uniform current distribution is large. The current distribution and redistribution among strands by cross-current is a very complex problem and further study is needed. Another possible contribution to the voltage drop is the non-uniform physical characteristics of each strand, such as the strain and diameter and critical current variation. Also, there will be a small contribution from the assumption that the magnetic field varies linearly across the radial direction while the large area of the conductor is covered by the lower magnetic field. Total voltage drop observed in the FENIX test could be explained by the combination of all these effects discussed above and more. However, a further study is needed to quantify these various contributions to the current sharing voltage drop.

\section{CONCLUSION}

During ITER conductor testing in the current sharing region at the FENIX facility, the conductor could be operated throughout a $1 \mathrm{~K}-2 \mathrm{~K}$ current sharing temperature range with voltage drop of less than $200 \mu \mathrm{V}$. The one-dimensional current sharing model used by the CICC computer code predicted a steeper rise in the voltage drop vs. temperature. This leads to the conclusion that cross-currents occur between the strands before the conductor reaches critical current in all strands. This inter-strand crosscurrent phenomena could be developed due to the radial magnetic ficld distribution, the initial non-uniform current distribution among strands, and the non-uniform critical current characteristics created by manufacturing.

\section{ACKNOWLEDGMENT}

This work was performed under the auspices of the U.S. Department of Energy by Lawrence Livennore National Laboratory under contract number W-7405-ENG-48.

\section{REFERENCES}

[1] N. Mitchell and L. Buttra, "Superconductors for the NET coils," Fusion Engineering and Design, 15 . 85. 1991

(2) P. Bruzzone. et al., "Test Results of Full Size 40 kA NET/TTER Conductor in the FENIX Test Facility," IEEE Trans. on Applied Superconductivity, Vol. 3, No. 1, pp357-360, March, 1993.

[3] R. W. Wong. "Program CICC, Flow and Heat Transfer in Cablein Conduit Conductors," Proc. of IEEE 13th Symp. on Fusion Engineering, Vol 2. pp1134-1137, 1989.

[4] S. S. Shen. "ITER Conductor Tests," Lawrence Livermore National Laboratory, UCRL-JC-108527, October, 1991.

[5] S. S. Shen, et al., "Testing of ITER Prototype Cable-in-Conduit Conductors in the FENIX Facility," Presented at 13 th Int. Conf. on Magnet Tecbnology, Victoria, British Columbia, Canada, September 1993.

[6] M. Sugimoto et al.. "Test Result of the FER/TER Conductors in the FENIX Test Facility," presented at MIT-13 Conference, Victoria, Canada, September 1993. 

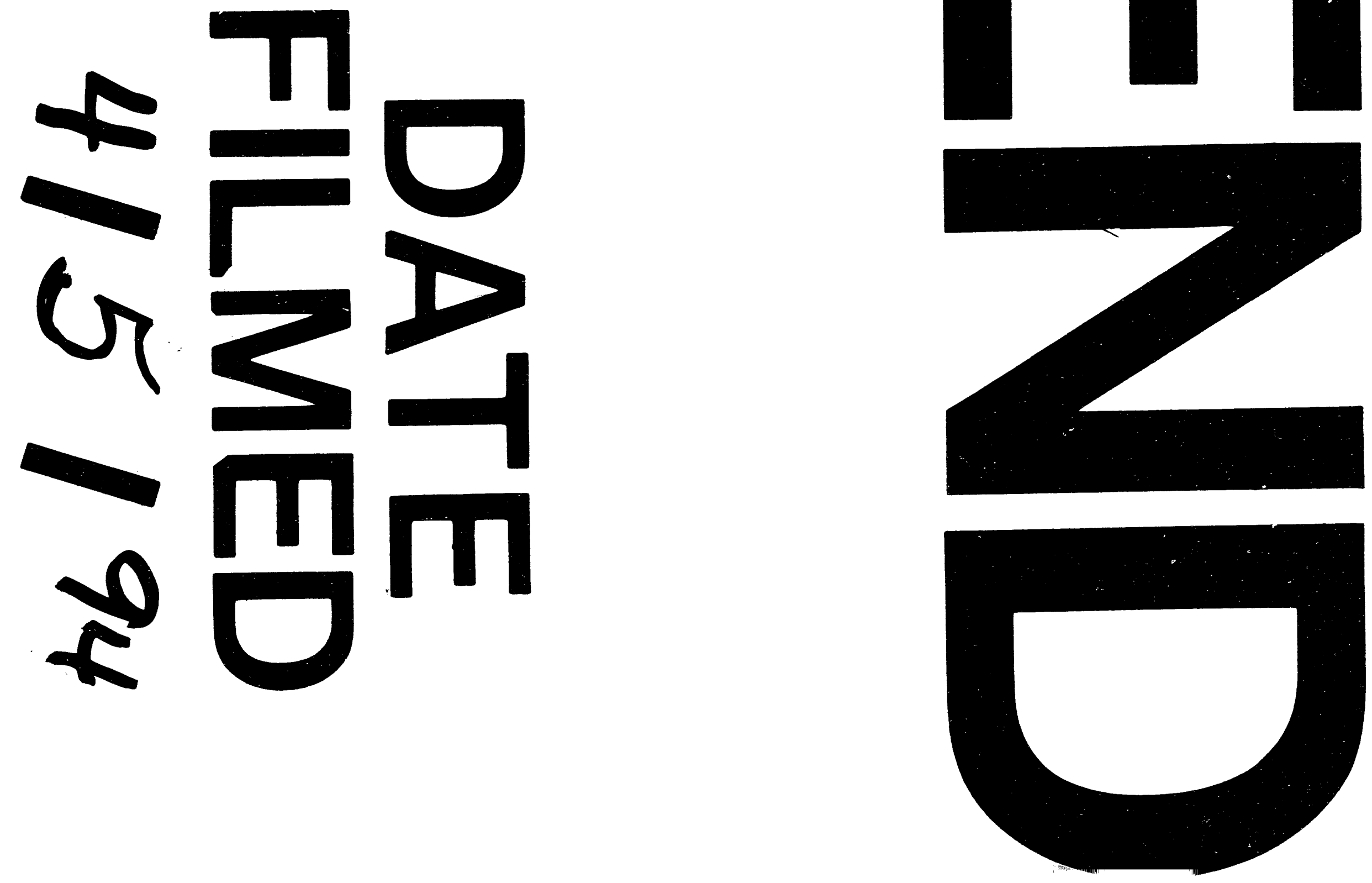
